\title{
Knowledge and attitudes of undergraduate medical students with regard to medical research at a South African university
}

\author{
A O Adefolalu, MB ChB, MPH, PhD; N J Mogosetsi, BSc Hons, MB ChB, Dip HIV Man (SA), MMed (Fam Med), FCFP (SA), PGDip (HPE); \\ N M Mnguni, $\mathrm{MB} \mathrm{ChB}, \mathrm{DOH}$
}

Practice of Medicine Unit, School of Medicine, Sefako Makgatho Health Sciences University, Pretoria, South Africa

Corresponding author: A O Adefolalu (adegoke.adefolalu@smu.ac.za)

\begin{abstract}
Background. The early introduction of medical students to medical research-related courses is one of the innovative solutions devised by medical schools to address the dearth of physician-scientists.

Objective. To describe the knowledge and attitudes of medical students towards medical research at a medical school where research and measurement skills are taught from the first year of study.

Methods. A validated, pretested self-administered questionnaire was employed in a cross-sectional study to collect data from 228 third- and fourthyear medical students at Sefako Makgatho Health Sciences University (SMU), Pretoria, South Africa in April 2017. Knowledge of medical research was assessed with a 15-item questionnaire, and attitude towards research was measured with a 10-item scale. The data were analysed with Epi Info (Centers for Disease Control and Prevention, USA) and findings are presented as means, percentages, proportions and tables. The $\chi^{2}$ test was used to assess association among the variables, with $p<0.05$ considered significant.

Results. The mean age of the 228 participants was 22.7 (standard deviation 2.55) years, with ages ranging between 19 and 36 years; $66.2 \%$ were female. Although only a few (22\%) had prior research experience and less than half (36\%) were confident to interpret medical research, the mean score on research knowledge was $73 \%$ and a positive attitude towards research was demonstrated. Statistical significance was found between having previous research experience and ability to interpret medical research $\left(\chi^{2}=12.8 ; p=0.01\right)$, and between age and having previous research experience $\left(\chi^{2}=35.7 ; p=0.01\right)$.

Conclusion. The findings revealed a good knowledge and positive attitude to medical research among the students. All these outcomes are the result of early exposure to medical research. More research-based courses are recommended for medical students, without overloading the medical curriculum.
\end{abstract}

Afr J Health Professions Educ 2018;10(4):205-209. DOI:10.7196/AJHPE.2018.v10i4.1022

Medical research as a component of undergraduate medical training is a very crucial aspect that has the potential of developing certain skills in students. These skills would serve as a means of improving the standard of healthcare that the students deliver after graduation by means of the generation of new scientific findings and introduction of good clinical practice ${ }^{[1,2]}$ Clinicians who are engaged in research in the field of medicine are often referred to as physician-scientists. ${ }^{[3]}$ The literature suggests that there has been a steady decline in the number of physician-scientists worldwide, who are very difficult to replace. Some of the reasons for this decline have been attributed to the absence of good training programmes, unattractive careers in clinical research, and inadequate exposure to research at an early stage of the medical curriculum. ${ }^{[3-5]}$ The need for more physicianscientists has resulted in the rapid expansion of medical research-related courses at several medical schools. This trend should expose undergraduate medical students to medical research-related courses at an early stage in their medical education, with emphasis on acquisition of skills, knowledge and attitudes rather than factual learning. All these would lead to students developing the habit and skills of active inquiry, which are inculcated for life. ${ }^{[4,6,7]}$ Furthermore, various studies have shown that medical students who were enthusiastic about medical research during training developed an interest in research after graduation. These doctors most likely fill the void of physician-scientists in the future. ${ }^{[2,4.8]}$

Courses in evidence-based medicine, which are crucial in clinical practice, have also been introduced into the medical curriculum, together with epidemiology, research methods and journal article critique at some South African (SA) universities. ${ }^{[9-11]}$ These courses have been shown to improve students' competencies at undergraduate level. ${ }^{[9-11]}$ According to the literature, there is sufficient evidence that medical curricula in SA medical schools have been through significant renewal in the past decade. ${ }^{[7,9-12]}$ Some of the outcomes include the early exposure of students to medical research as part of the modernisation of the undergraduate medical curriculum. ${ }^{[7]}$ There is a strong indication that the quality of doctors would be highly influenced by this renewed curriculum..$^{[7,13]}$ Despite all the recent innovation regarding medical curricula in SA, a review of the literature showed very little information on the knowledge and attitudes of medical students in sub-Saharan Africa towards medical research. Therefore, this study was designed to describe the knowledge and attitudes of a sample of undergraduate medical students at a SA university with regard to medical research.

\section{Methods \\ Study design and setting}

This was a descriptive, cross-sectional observational study conducted among medical students at Sefako Makgatho Health Sciences University (SMU), Pretoria, SA, one of eight public-funded medical schools in SA that provides training to medical, dental and other allied healthcare professionals. ${ }^{[14]}$ The university offers a 6 -year undergraduate medical programme that has adopted the innovative case-based learning $(\mathrm{CBL})$ 
approach in the teaching and learning of undergraduate medical students. The CBL approach as an educational strategy adopted at SMU stresses that students develop lifelong self-directed learning skills, construct an extensive and flexible knowledge base and effective problem-solving skills. Various aspects of research and measurement skills are taught from the first to the sixth year of study. This gives the students the opportunity of being exposed to courses in research methods, referencing styles, epidemiology, evidencebased medicine and clinical audits and how to critique scientific journal articles. The introduction of these skills is in line with new trends in medical education worldwide as a response to the abovementioned decline in the number of physician-scientists. ${ }^{[3,5,7]}$

\section{Sampling}

The researchers sampled the third- and fourth-year students owing to their accessibility and attributes; they had already been exposed to some of the research and measurement skills in their previous years of study. Nonprobability sampling was deemed feasible because the first- and second-year students were being taught courses on which the study questionnaires were based and were therefore not suitable. The fifth- and sixth-year students were in their clinical rotations in different training settings; therefore, it would have been difficult to do a cross-sectional study involving them. At the time of the research there were $\sim 500$ medical students in both the third and fourth years of study. Convenience sampling was used for an equal number of participants from both classes; the data were not contaminated. The prevalence of adequate knowledge was estimated at $50 \%$ or 0.5 , with an absolute error of 0.05 . A total of 218 students were required based on finite correction. A $~ 5 \%$ non-response rate was added, making the final sample 230 students.

\section{Data collection}

A self-administered closed-ended questionnaire was designed after a thorough literature review. It had been pre-tested in 10 medical students in their fifth year of study, who were not part of the final participants selected for the study, and subsequently amended for both clarity and content validity. The fifth year was used for this purpose, because convenience sampling was to be used during data collection and the researchers did not want to contaminate the data. It would have been difficult to exclude third- or fourth-year students during data collection. The questionnaire contained information with regard to knowledge and attitude of medical students towards medical research. Data collection was done in mid-April 2017 during lectures, when the majority were in attendance. Questionnaires $(n=115)$ were handed out at each class, i.e. a total of 230 . These were distributed to all consenting students who were present at class lectures; no randomisation was done. The researchers handed out 115 questionnaires to students, which they returned after completion.

\section{Ethical approval}

Ethical approval was obtained from the SMU Research and Ethics Committee (ref. no. SMUREC/M/186/2016) and all the participants gave signed, written informed consent before participating in the study.

\section{Study variables}

Demographical data, such as age, gender and prior research experience, were collected. Knowledge of medical research was measured using a 15-item multiple-choice questionnaire. Each question had 5 options and 1 correct answer $(\mathrm{A}-\mathrm{E})$. The attitude towards research was assessed with a 10-item scale with 3 options, i.e. 'yes', 'no' or 'undecided'. Examples of questions are as follows: 'Do you feel confident in interpreting a medical research article?'; and 'Do you think that medical research ethics is relevant and important?'

\section{Statistical analysis}

All the returned questionnaires, except 2, were completed, which were returned almost blank, with the respondents completing only the demographic data. These 2 questionnaires were excluded from the rest and a total of 228 questionnaires were collated, captured and analysed. The collected data were cleaned, checked for errors and captured onto an Excel spreadsheet initially. The data were subsequently analysed using Epi Info (Centers for Disease Control and Prevention, USA). Descriptive statistics were done, and data were presented using frequencies, means, standard deviations, proportions and percentages, as appropriate. The assessed students' knowledge of medical research was analysed and compared across age, gender, prior research experience and ability to interpret a journal article. The $\chi^{2}$ test was used to assess the association among the variables and a critical $p=0.05$ was regarded as statistically significant.

\section{Results}

The mean age of the 228 participants was 22.7 (standard deviation (SD) 2.55) years, mode was 20 years and median was 22 (range 19 - 36) years. As shown in Table 1, in terms of gender distribution, 77 (33.8\%) were male and $151(66.2 \%)$ were female. Table 2 indicates the response of medical students to knowledge of medical research. The mean score on the 15-item questionnaire that assessed research knowledge was $73 \%$, while the expected average score for each question was $70 \%$. Therefore, if the participants' mean score was $>70 \%$ in any of the 15 questions, it is described as having good knowledge of that question. The result indicates that participants performed well in 10 of the 15 questions (i.e. scored $>70 \%$ ). They performed poorly in the question regarding the best study design that allows for causality; the correct answer was a randomised controlled trial $(<10 \%$ of participants answered the question correctly). The other question where the participants did not do well was to differentiate various types of observational studies $<50 \%$ answered this correctly. Table 3 depicts the students' responses to their attitudes toward medical research. In most cases the majority agreed that the inclusion of research article critique skills in the medical curriculum is important (91\%); evidence-based medicine is relevant and important (91\%); and medical research ethics is relevant and important (94\%).

\begin{tabular}{ll} 
Table 1. Characteristics of participants $(\mathbf{N}=\mathbf{2 2 8})$ \\
\hline Characteristics & Participants \\
\hline Age (years), mean (SD) & $22.7(2.55)$ \\
Sex, $n$ (\%) & $77(33.8)$ \\
$\quad$ Male & $151(66.2)$ \\
$\quad$ Female & \\
Previous research experience, $n(\%)$ & $50(22)$ \\
$\quad$ Yes & $178(78)$ \\
$\quad$ No & \\
Ability to interpret research, $n(\%)$ & $147(36)$ \\
$\quad$ Yes & \\
$\quad$ No & \\
SD $=$ standard deviation. &
\end{tabular}


The mean scores on research knowledge of the third- and fourth-year medical students were compared; there was no statistically significant difference $(p>0.05)$. The average score on research knowledge was $73.4 \%$ and $72.6 \%(p>0.05)$ for third- and fourth-year students, respectively. Table 4 shows the segregation of participants with a positive attitude towards medical research. There were no major differences between the third- and fourth-year students across the questions that assessed their attitudes towards research, except in the area of research exposure, where
$54 \%$ of fourth-year students and $46 \%$ of third-year students had previous experience.

The $\chi^{2}$ test of association was applied to some of the variables to establish whether there is an association between them, but there was no statistically significant association between age and ability to interpret medical research $\left(\chi^{2}=10.6 ; p=0.10\right)$, between gender and ability to interpret medical research $\left(\chi^{2}=2.9 ; p=0.24\right)$, between gender and having previous research experience $\left(\chi^{2}=1.71 ; p=0.42\right)$ and between having previous research experience and

Table 2. Participants' knowledge scores of medical research $(N=228)$

\begin{tabular}{ll}
\hline Knowledge & Correctly answered, $\boldsymbol{n}$ (\%) \\
\hline The focus of epidemiological studies is on ... ? & $224(98.0)$ \\
Sampling in research reflects ... ? & $211(92.5)$ \\
The following are types of observational studies, except ... ? & $111(48.7)$ \\
The ability of a screening test to correctly identify individuals who don't have the disease is called ... ? & $125(54.8)$ \\
In the hierarchy of evidence, what method gives the most reliable evidence? & $204(89.5)$ \\
The constraints or problems faced by researchers in the study are known as ... ? & $208(91.0)$ \\
We do literature review in research to know ... ? & $149(65.4)$ \\
The most frequently occurring observation in a data set is ... ? & $186(81.6)$ \\
In medical research articles, an abstract is ... ? & $165(72.4)$ \\
Outline of a scientific report include the following, except ... ? & $167(73.3)$ \\
The study design is most useful in investigating causality between exposure and outcome & $19(8.3)$ \\
Prevalence of a disease refers to ... ? & $180(79.0)$ \\
Which one of the following is used to reduce bias in a study ... ? & $209(91.7)$ \\
The confidence interval is ... ? & $138(60.5)$ \\
Which one of the following is not an acceptable ethical standard in medical research? & $180(79.0)$
\end{tabular}

Table 3. Participants' responses with regard to attitude towards medical research $(N=228)$

\begin{tabular}{llll}
\hline Responses & Yes, $\boldsymbol{n}(\%)$ & No, $\boldsymbol{n}(\%)$ & Undecided, $\boldsymbol{n}$ (\%) \\
\hline Do you feel confident in interpreting a medical research article? & $81(35.5)$ & $80(35.1)$ & $67(29.4)$ \\
Do you think that the epidemiology block is relevant and important? & $182(79.8)$ & $30(13.2)$ & $16(7.0)$ \\
Do you think that the epidemiology block is appropriately placed in first year? & $134(58.8)$ & $76(31.6)$ & $22(9.6)$ \\
Do you think that medical research article critique is relevant and important? & $207(90.8)$ & $11(4.8)$ & $10(4.4)$ \\
Do you think that the research article critique block is appropriately placed in second year? & $165(72.4)$ & $45(19.7)$ & $18(7.9)$ \\
Do you think evidence-based medicine is relevant and important? & $207(90.8)$ & $10(4.4)$ & $11(4.8)$ \\
Do you think that evidence-based medicine is appropriately placed in third year? & $173(75.9)$ & $29(12.7)$ & $26(11.4)$ \\
Do you think that medical research ethics is relevant and important? & $214(93.9)$ & $4(1.8)$ & $10(4.4)$ \\
Do you think undergraduate students should undertake research activity? & $138(60.5)$ & $51(22.4)$ & $39(17.1)$ \\
Do you have previous exposure to research, except at undergraduate level at medical school? & $50(21.9)$ & $175(76.8)$ & $3(1.3)$
\end{tabular}

\section{Table 4. Comparison of attitude towards medical research between third- and fourth-year students}

\section{Attitude}

Do you feel confident in interpreting a medical research article? $(n=81)$

Do you think that the epidemiology block is relevant and important? $(n=182)$

Do you think that the epidemiology block is appropriately placed in first year? $(n=134)$

Do you think that medical research article critique is relevant and important? $(n=207)$

Do you think that the research article critique block is appropriately placed in second year? $(n=165)$

Do you think that evidence- based medicine is relevant and important? $(n=207)$

Do you think that evidence-based medicine is appropriately placed in third year? $(n=173)$

Do you think that medical research ethics is relevant and important? $(n=214)$

Do you think undergraduate students should undertake research activity? $(n=138)$

Do you have previous exposure to research, except at undergraduate level at medical school? $(n=50)$

\begin{tabular}{ll}
\multicolumn{3}{c}{ Answer: yes } \\
\hline Third year, & Fourth year, \\
$\boldsymbol{n}(\%)$ & $\boldsymbol{n}(\%)$ \\
$42(52)$ & $39(48)$ \\
$90(49)$ & $92(51)$ \\
$70(52)$ & $64(48)$ \\
$100(48)$ & $107(52)$ \\
$85(52)$ & $80(48)$ \\
$100(48)$ & $107(52)$ \\
$86(50)$ & $87(50)$ \\
$103(48)$ & $111(52)$ \\
$69(50)$ & $69(50)$ \\
$23(46)$ & $27(54)$
\end{tabular}


belief in the importance of medical research $\left(\chi^{2}=2.8 ; p=0.58\right)$. Using the $\chi^{2}$ test, a statistical significance was found between having previous research experience and ability to interpret medical research $\left(\chi^{2}=12.8 ; p=0.01\right)$ and between age and having previous research experience $\left(\chi^{2}=35.7 ; p=0.01\right)$.

\section{Discussion}

This study showed that the participants had a good knowledge of medical research, which differs greatly from similar studies among Pakistani and Croatian medical students, where the mean score on medical research knowledge was poor. ${ }^{[4,15]}$ However, the medical students in both studies showed a positive attitude towards medical research. ${ }^{[4,15]}$ In another SA study, the majority of medical students also demonstrated a positive attitude towards medical research, and almost the same proportion of these participants and those in the current study had similar research experience. ${ }^{[6]}$ One would have expected the fourth-year students to have a higher average score than those in their third year, but the current study revealed otherwise. The reason could be that the third-year students might have found it easier to recall the answers to some of the questions on research knowledge than those in the fourth year. The questions on medical research were based on medical research-based courses, which are offered in the first and second year of study at SMU.

Having previous research experience was found to be associated with the ability to interpret medical research; this is highly suggestive of the assertion that students who had prior research experience are better placed to understand the concepts of medical research than others. The association between age and having previous research experience points to older students being likely to have had previous research experience.

As mentioned above, there is growing concern globally among clinical scientists about the dearth of physician-scientists, who are saddled with the responsibility of generating new clinical knowledge that we use in the practice of medicine through cutting-edge research. ${ }^{[3,7]}$ The consequences for clinical practice would be lack of quality research, which is necessary for the delivery of evidence-based medical care. ${ }^{[5,7]}$ Fortunately, a good number of medical schools have already responded to this with the early introduction of research courses into their medical curriculum, together with encouragement of student participation in research activities during their medical training. ${ }^{[7,9-11]}$ All of this is done to foster favourable attitudes towards medical research among students. ${ }^{[3,6,7,9-11]}$ Anecdotal evidence suggests that this innovation has improved knowledge and attitudes of students regarding medical research significantly, as shown in the current study. ${ }^{[9-11]}$ Furthermore, earlier studies that attempted to determine the level of knowledge and attitudes of medical students towards research revealed that students who have been involved in research activities performed academically well during their postgraduate studies. ${ }^{[4,7,13]}$ Therefore, medical research forms an important aspect of undergraduate medical education that is highly relevant to any doctor who seeks to practise medicine, where there is an ever-increasing body of information in the field of medicine globally. ${ }^{[3,7]}$

Having a good grasp of scientific methodology is vital to future doctors, who have to understand the principles of scientific research, develop skills necessary to collect data, and analyse and subsequently disseminate knowledge in a form of a research article in a peer-reviewed journal. ${ }^{[7,8,11,16]}$ Furthermore, the vast amount of available information in various medical disciplines implies that these future doctors need to be able to evaluate and critique medical research articles to apply best evidence in their clinical practice, as informed by research. ${ }^{[7,13]}$ As shown in our study, medical students have a positive attitude towards research, but very few are able to confidently interpret a research article at this stage. They were in third and fourth year at the time of the study - their performance will possibly improve as they proceed to fifth and sixth year. Therefore, their good knowledge and positive attitude are most likely a consequence of their early exposure to research-related courses.

\section{Conclusion}

Although very few of the students had research experience before entering medical school and a minority were fully confident of interpreting scientific journal articles, the majority agreed that undergraduate medical students should be involved in research activities. The research and measurement skills taught at an early stage of medical training are aimed at developing critical thinking and reasoning skills. ${ }^{[3,7]}$ It also enables them to develop a positive attitude towards medical research from a very early stage of their career, with the hope that some would become physician-scientists after graduation. ${ }^{[3,7]}$ In view of the abovementioned reasons, it is therefore important to inculcate critical thinking and a positive attitude towards research into medical students at an early stage in their training by a variety of research and measurement courses. ${ }^{[3,7,10,13]}$

Epidemiology, public health, health systems, research methods, evidencebased medicine and journal article critique are some of the research and measurement courses being offered at some of SA universities..$^{[7,9,10-12]}$ It is highly recommended that these form part of the undergraduate medical curriculum at all medical schools. Future studies into research and measurement skills knowledge among medical students are also needed, which should use a larger multicentred design and consider a longitudinal study that will measure variables over time.

\section{Study limitations}

Our study was limited by its cross-sectional design. Causation is difficult to establish in cross-sectional studies, and a longitudinal study could have allowed for the assessment of students' knowledge and attitudes over time. Recall or memory bias is a problem when outcomes being measured require that subjects recall past events. Often a person recalls positive events more easily than negative ones. This limitation was minimised by affording the participants enough time to recall information required to complete the questionnaires. The study was conducted in only one medical school; the findings should therefore be interpreted with caution in terms of generalising these to other medical schools.

\section{Declaration. None.}

Acknowledgements. The authors would like to thank all medical students who participated in the research, as well as the management of Sefako Makgatho Health Sciences University that granted permission to conduct the study. The authors gratefully acknowledge the contribution of Devon Hough (medical student, SMU) for capturing the data.

Author contributions. AOA and NJM: study conception and design; NJM and NMM: data collection; AOA: data analysis, data interpretation and drafting of the initial manuscript; and NJM and NMM: review and revision of the manuscript for important intellectual content. All three authors reviewed and agreed on the final version of the article before submission.

Funding. None.

Conflicts of interest. None. 
1. Hmelo-Silver CE. Problem-based learning: What and how do students learn? Educ Psychol Rev 2004;16(3):235-266 https://doi.org/10.1023/B:EDPR.0000034022.16470.f3

2. Prideaux D. Curriculum development in medical education: From acronyms to dynamism. Teach Teach Educ 2007;23:294-302. https://doi.org/10.1016/j.tate.2006.12.017

3. Mayosi BM, Dhai A, Folb P, et al. Consensus Report on Revitalising Clinical Research in South Africa: A Study on Clinical Research and Related Training. Pretoria: Academy of Science of South Africa, 2009. http://www.assaf. co.za/wp-content/uploads/2009/09/ASSAf-Clinical-Report-2009.pdf (accessed 10 February 2018).

4. Khan $\mathrm{H}$, Khawaja $\mathrm{M}$, Waheed $\mathrm{A}$, et al. Knowledge and attitudes about health research among a group of Pakistan medical students. BMC Med Educ 2006;6:54. https://doi.org/10.1186/1472-6920-6-54

5. Neilson EG. The role of medical school admissions committees in the decline of physician-scientists. J Clin Invest 2003;111(6):765-767. https://doi.org/10.1172/JCI200318116

6. Nel D, Burman RJ, Hoffman R, Randera-Rees S. The attitudes of medical students to research. S Afr Med J 2014;104(1):32-36. https://doi.org/10.7196/samj.7058

7. Seggie JL. MB ChB curriculum modernisation in South Africa - growing doctors for Africa. Afr J Health Professions Educ 2010;2(1):8-14.

8. Pugsley L, McCrories P. Improving medical education: Improving patient care. Teach Teach Educ 2007;23(3):314322. https://doi.org/10.1016/j.tate.2006.12.023

9. Burger M, Louw QA. Integrating evidence-based principles into the undergraduate physiotherapy research methodology curriculum: Reflections on a new approach. Afr J Health Professions Educ 2014;6(2 Suppl 1):198-202. https://doi.org/10.7196/ajhpe.516
10. Knight SE, van Wyk JM, Mahomed S. Teaching research: A programme to develop research capacity in undergraduate medical students at the University of KwaZulu-Natal, South Africa. BMC Med Educ 2016;16:6 https://doi.org/10.1186/s12909-016-0567-7

11. Dudley LD, Young TN, Rowher AC, et al. Fit for purpose? A review of a medical curriculum and its contributio to strengthening health systems in South Africa. Afr J Health Professions Educ 2015;7(1 Suppl 1):81-85. https:// doi.org/10.7196/AJHPE.512

12. Reid S. The 'medical humanities' in health sciences education in South Africa. S Afr Med J 2014;104(2):109-110. https://doi.org/10.7196/samj.7928

13. Van der Merwe L), van Zyl G J, St Clair Gibson A, et al. South African medical schools: Current state of selection criteria and medical students' demographic profile. S Afr Med J 2016;106(1):76-81. https://doi.org/10.7196/ SAMJ.2016.v106i1.9913

14. Health Professions Council of South Africa. Medical and dental education and training. http://www.hpcsa.co.za/ PBMedicalDental/Education (accessed 15 February 2018).

15. Vodopivec I, Vujaklija A, Hrabak M, et al. Knowledge about and attitude towards science of first year medical students. Croat Med J 2002;43:58-62.

16. Noorelahi MM, Soubhanneyaz AA, Kasim KA. Perceptions, barriers, and practices of medical research among students at Taibah College of Medicine, Madinah, Saudi Arabia. Adv Med Educ Pract 2015;6:479-485. https:// doi.org/10.2147/AMEP.S83978

Accepted 27 March 2018. 